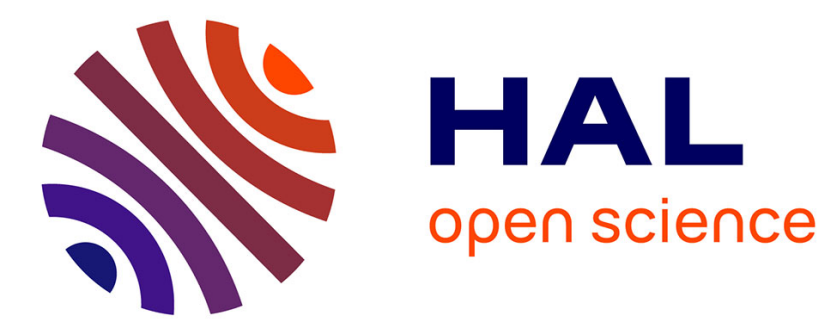

\title{
Some terms of reference in data fusion
}

Lucien Wald

\section{To cite this version:}

Lucien Wald. Some terms of reference in data fusion. IEEE Transactions on Geoscience and Remote Sensing, 1999, 37 (3), pp.1190-1193. 10.1109/36.763269 . hal-00356150

\section{HAL Id: hal-00356150 https://hal.science/hal-00356150}

Submitted on 26 Jan 2009

HAL is a multi-disciplinary open access archive for the deposit and dissemination of scientific research documents, whether they are published or not. The documents may come from teaching and research institutions in France or abroad, or from public or private research centers.
L'archive ouverte pluridisciplinaire HAL, est destinée au dépôt et à la diffusion de documents scientifiques de niveau recherche, publiés ou non, émanant des établissements d'enseignement et de recherche français ou étrangers, des laboratoires publics ou privés. 


\title{
SOME TERMS OF REFERENCE IN DATA FUSION
}

\author{
Wald Lucien
}

\begin{abstract}
This paper discusses the needs for a concept and harmonized terms of reference in data fusion. Already published definitions are analyzed. A new definition of the data fusion is proposed which has been set within an European working group. Several definitions and terms of reference are given which describe the information intervening in any problem of data fusion.
\end{abstract}

Index terms - data fusion, concepts, definitions, remote sensing

Wald L., 1999. Some terms of reference in data fusion. IEEE Transactions on Geosciences and Remote Sensing, 37, 3, 1190-1193.

\section{THE NEED FOR CONCEPT AND TERMS OF REFERENCE}

The concept of data fusion is easy to understand. However its exact meaning varies from one scientist to another. Several words have appeared, such as merging, combination, synergy, integration, ... All of them appeal more or less to the same concept but are however felt differently. Several times, the word « fusion » is used while « classification» would be more appropriate, given the contents of the publication. There is a need for terms of reference in the remote sensing community, which has been strongly expressed in several meetings. A working group, set up by the European Association of Remote Sensing Laboratories (EARSeL) and the French Society for Electricity and Electronics (SEE, French affiliate of the IEEE), devoted most of its efforts to establish a lexicon or terms of reference, which is presented in this article.

This is not the only attempt to set up definitions in data fusion. The remote sensing community should not establish terms which are also used elsewhere with different meanings. Therefore, whenever possible, definitions were adopted which are already widely used in the broad scientific community, especially that dealing with information. Examples of such terms are image, features, symbols, etc.

Several lexicons have been already set up which have been established in the framework of the Defence domain (e.g., US Department of Defence [1]; DSTO [2]). It was found

Groupe Télédétection \& Modélisation, Ecole des Mines de Paris, BP 207, 06904 Sophia Antipolis cedex, France that it is not easy to translate military terms in meaningful words for the scientific community dealing with Earth observation: this would imply a refinement of the military terms to expand their meaning, with a reference to the timespace scales. It was concluded that using an existing lexicon is not straightforward, and that a new one is required to tackle the specific needs of our community. However we should benefit from these previous works as much as possible, and, whenever possible, we should use the terms already adopted.

\section{A DEFINITION OF DATA FUSION}

Data fusion means a very wide domain and it is very difficult to provide a precise definition. This large domain cannot be simply defined by restricting it, for example, to specific wavelengths, or specific acquisition means, or specific applications. A fusion process may call upon so many different mathematical tools that it is also impossible to define fusion by these tools.

Several definitions can be found in the literature. Pohl, Van Genderen [3] proposed « image fusion is the combination of two or more different images to form a new image by using a certain algorithm », which is restricted to images. Mangolini [4] extends data fusion to information in general and also refers to quality. He defines data fusion as a « set of methods, tools and means using data coming from various sources of different nature, in order to increase the quality (in a broad sense) of the requested information ». However, these definitions put the accent on the methods. They contain the large diversity of tools, but are restricted to these. Hall, Llinas [5] also refer to information quality in their definition but still focus on the methods: « data fusion techniques combine data from multiple sensors, and related information from associated databases, to achieve improved accuracy and more specific inferences that could be achieved by the use of a single sensor alone $»$.

The US Department of Defence [1] stated that « data fusion is a multilevel, multifaceted process dealing with the automatic detection, association, correlation, estimation, and combination of data and information from multiple sources ». This definition was refined in [6] as a «multilevel, multifaceted process dealing with the automatic detection, association, correlation, estimation, and combination of data and information from single and 
Wald L., 1999. Some terms of reference in data fusion. IEEE Transactions on Geosciences and Remote Sensing, 37, 3, 11901193.

multiple sources ». This definition is more general with respect to the types of information than can be combined (multilevel process). Quality is dealt with through the level 4 processing "process refinement". Li et al. [7] wrote « fusion refers to the combination of a group of sensors with the objective of producing a single signal of greater quality and reliability ». Quality and reliability are referred to, but there is no reference to concepts. Furthermore it is restricted to sensors and signal.

It is often written that fusion takes place at three levels in data fusion: pixel, attribute and decision [3] [4] [8] [9]. It presents two drawbacks. The word "pixel" is inappropriate here ; the pixel is only a support of information and has no semantic significance. Measurements or observations or signal would be more appropriate. But overall, such a categorization may be misleading: it may falsely imply that fusion processes do not deal simultaneously with these different levels. In Earth observation domain, one may use some features (attribute level) held in a geographical information system to help in classifying multispectral images (measurement level) provided by several sensors. In this particular case, some data are measurements of energy, and others may be symbols. The formalism of Houzelle, Giraudon [10] is preferable. It allows all semantic levels (measurements, attributes, decisions) to be simultaneous inputs of a fusion process. Wald [11] presented several examples of this formalism applied to remote sensing.

Finally it was felt that most of these definitions were focusing too much on methods though paying some attention to quality. As a whole, there is no reference to concept in these definitions while the need for a conceptual framework was clearly expressed by the scientists as well as practitioners.

A search for a more suitable definition was launched with the following principles. The definition for data fusion should not be restricted to data output from sensors (signal). It should neither be based on the semantic levels of the information. It should not be restricted to methods and techniques or architectures of systems, since we aim at setting up a conceptual framework for data fusion. Based upon the works of Buchroithner [12] and Wald [13], the following definition was adopted in January 1998: « data fusion is a formal framework in which are expressed means and tools for the alliance of data originating from different sources. It aims at obtaining information of greater quality; the exact definition of 'greater quality' will depend upon the application ». (in French: la fusion de données constitue un cadre formel dans lequel s'expriment les moyens et techniques permettant l'alliance des données provenant de sources diverses. Elle vise à l'obtention d'information de plus grande qualité ; la définition exacte de «plus grande qualité » dépendra de l'application.)

This definition is clearly putting an emphasis on the framework and on the fundamentals in remote sensing underlying data fusion instead of on the tools and means themselves, as is done usually. The latter have obviously strong importance but they are only means not principles. A review of methods and tools can be found in [2]-[3].

Secondly it is also putting an emphasis on the quality. This is certainly the aspect missing in most of the literature about data fusion, but one of the most delicate. Here quality has not a very specific meaning. It is a generic word denoting that the resulting information is more satisfactory for the « customer » when performing the fusion process than without it. For example, a better quality may be an increase in accuracy of a geophysical parameter or of a classification. It may also be related to the production of a more relevant information of increased utility, or to the robustness in operational procedures. Greater quality may also mean a better coverage of the area of interest, or a better use of financial or human resources allotted to a project.

In this definition, spectral channels of a same sensor are to be considered as different sources, as well as images taken at different instants. Hence, any processing of images acquired by the same sensor is relevant to the data fusion domain, such as classification of multispectral imagery, or computation of the NDVI (normalized difference vegetation index), or atmospheric correction of spectral bands using other bands of the same sensor. Any processing of time-series of data acquired by the same sensor or different sensors, is a fusion process.

\section{OTHER DEFINITIONS}

It then has been suggested to use the terms merging, combination in a much broader sense than fusion, with combination being even broader than merging. These two terms define any process that implies a mathematical operation performed on at least two sets of information. These definitions are intentionally loose and offer space for various interpretations. Merging or combination are not defined with an opposition to fusion. They are simply more general, also because we often need such terms to describe processes and methods in a general way, without entering details. Integration may play a similar role though it implicitly refers more to concatenation (i.e. increasing the state vector) than to the extraction of relevant information.

Another domain pertains to data fusion: data assimilation or optimal control. Data assimilation deals with the inclusion of measured data into numerical models for the forecasting or analysis of the behavior of a system. A well-known example of a mathematical technique used in data assimilation is the Kalman filtering. Data assimilation is daily used for weather forecasting.

Terms like measurements, attributes, rules or decisions, are often used in data fusion. These terms as well as others related to information are defined in the following. These 
Wald L., 1999. Some terms of reference in data fusion. IEEE Transactions on Geosciences and Remote Sensing, 37, 3, 11901193.

definitions are those used in information science and have been found in several publications [14]- [17].

Measurements are primarily the outputs of a sensor. It is also called signal, or image in the 2-D case. The elementary support of the measurement is a pixel in the case of an image, and is called a sample in the general case. By extension, measurement denotes the raw information. For example, a verbal report is a piece of raw information, and may be considered as a signal. In remote sensing, in the visible range, the measurements are digital numbers that can be converted into radiances once the calibration operations performed. If corrections for the sun angle are applied, one may get reflectances which are still considered as signal.

An object is defined by its properties, e.g., its color, its materials, its shapes, its neighborhood, etc. It can be a field, a building, the edge of a road, a cloud, an oceanic eddy, etc. For example, if a classification has been performed onto a multispectral image, the pixels belonging to the same class can be spatially aggregated. This results into a map of objects having a spatial extension of several pixels. By extension, a pixel may be considered as an object.

An attribute is a property of an object. Feature is equivalent to attribute. For example, the classification of a multispectral image allocates a class to each pixel; this class is an attribute of the pixel. The equivalent terms label, category or taxon are also used in classification. Another well-known example is the spatial context of a pixel, computed by local variance, or structure function or any spatial operator. This operation can be extended to time context in the case of time-series of measurements. Equivalent terms are local variability, local fluctuations, spatial or time texture, or pattern. By extension, any information extracted from an image (or mono-dimensional signal) is an attribute for the pixel or the object. The aggregation of measurements made for each of the elements of the object (for example, the pixels or samples constituting the object), such as the mean value, is an attribute. Some authors call mathematical attribute such attribute deriving from statistical operations on measurements.

The properties of an object constitute the state vector of this object. This state vector describes the object, preferably in an unique way. The state vector is also called feature vector, or attribute vector. The common property of the elements of the state vector is that they all describe the same object. If the object is a pixel (or a sample), the state vector may contain the measurements as well as the attributes extracted from the processing of the measurements.

$\underline{\text { Rules, }}$ like the syntax rules in language, define relationships between objects and their state vectors, and also between attributes of a same state vector. Rules may be state equations, or mathematical operations, or methods (that is a suite of operations, i.e. of elementary rules). They may be expressed in elaborated language. Known examples of such rules are those used in artificial intelligence and expert-systems. Decisions result from the application of rules on a set of rules, objects and state vectors.

Usually, fusion of measurements results into attributes, and fusion of attributes into decisions. It is not always straightforward. Consider the case of the ARSIS concept which increases the spatial resolution of a multispectral image given another image of a better resolution not necessarily acquired in the same spectral bands [18] [19]. It intends to simulate what would be observed by a multispectral sensor having a better spatial resolution. Accordingly, it simulates measurements through a fusion process and inference models. However, the results are not measurements, but rather simulated attributes. Since they are obtained at each pixel, and since the calibration is taken into account during the process, these attributes are similar to actual measurements.

\section{TOPOLOGICAL AND PROCESSING ISSUES}

A fusion system can be a very complicated system. It is composed of sources of information, of means of acquisition of this information, of communications for the exchange of information, of intelligence to process the information and to issue information of higher content. The issues involved may be separated in topological and processing issues. Despite the interconnection between both issues in an integrated fusion system design, they can be decoupled from each other in order to facilitate the development of a systematic methodology of analysis and synthesis of a fusion system according to e.g., Thomopoulos [20] [21].

The topological issues address the problem of spatial distribution of sensors, the communication network between sensors and places of processing and decisionmaking, bandwidth and global architecture. Also at stake are issues for the exchange of information, the availability and reliability of information at the time of the fusion. The cost of acquiring the information may also be relevant to the topological issues. In remote sensing, these issues are partly addressed by the space agencies and by the image vendors. It is also partly addressed by the customer, given its objectives and constraints, including the financial budget.

The processing issues address the question of how to fuse the data, i.e. select the proper measurements, determine the relevance of the data to the objectives, select the fusion methods and architectures, once the data are available, and according to the specifications issued by the project under concern. These issues are mathematically expressed in Pau [22]. 
Wald L., 1999. Some terms of reference in data fusion. IEEE Transactions on Geosciences and Remote Sensing, 37, 3, 11901193.

\section{CONCLUSION}

A new definition of the data fusion has been proposed which better fits the remote sensing domain. Data fusion should be seen as a framework, not merely as a collection of tools and means. This definition emphasizes the concepts and the fundamentals in remote sensing. Several other terms are also proposed which for most of them are already widely used in the scientific community, especially that dealing with information.

The establishment of a lexicon or terms of reference allows the scientific community to express the same ideas using the same words, and also to disseminate their knowledge towards the industry and 'customers' communities.

Moreover it is a sine qua non condition to set up clearly the concept of data fusion and the associated formal framework. Such a framework is mandatory for a better understanding of data fusion fundamentals and of its properties. It allows a better description and normalization of the potentials of synergy between the remote sensing data, and accordingly, a better exploitation of these data.

Finally the introduction of the concept of data fusion into the remote sensing domain should raise the awareness of our colleagues on the whole chain ranging from the sensor to the decision, including the management, assessment and control of the quality of the information.

\section{ACKNOWLEDGMENTS}

This work has been made thanks to many fruitful discussions with several researchers and the many participants to the EARSeL - SEE working group "data fusion". I also thank Luce Castagnas, Isabelle Couloigner, Louis-François Pau, and Stelios Thomopoulos for their comments and assistance. I acknowledge the help of the referees of this paper who helped me in making it clearer.

\section{REFERENCES}

[1] U.S. Department of Defence, Data Fusion Subpanel of the Joint Directors of Laboratories, Technical Panel for C3, "Data fusion lexicon," 1991.

[2] DSTO (Defence Science and Technology Organization) Data Fusion Special Interest Group, Data fusion lexicon. Department of Defence, Australia, 7 p., 21 September 1994.

[3] C. Pohl, and J. L. van Genderen, "Multisensor image fusion in remote sensing: concepts, methods and applications", International Journal of Remote Sensing, vol. 19, n ${ }^{\circ}$ 5, pp. 823-854, 1998.

[4] M. Mangolini, Apport de la fusion d'images satellitaires multicapteurs au niveau pixel en télédétection et photo-interprétation. Thèse de Doctorat, Université Nice - Sophia Antipolis, France, 174 p., 1994.

[5] D. L. Hall, and J. Llinas, "An introduction to multisensor data fusion," (invited paper) in Proceedings of the IEEE, vol. 85, $\mathrm{n}^{\circ} 1, \mathrm{pp}$. 6-23, 1997.
[6] L. A. Klein, "Sensor and Data Fusion Concepts and Applications," SPIE Optical Engineering Press, Tutorial Texts, vol. 14, 132 p., 1993.

[7] H. Li, B. S. Manjunath, and S. K. Mitra, "Multisensor image fusion using the wavelet transform," Computer Vision, Graphics, and Image Processing: Graphical Models and Image Processing, vol. 57, pp. 235-245, 1993.

[8] G. Brandstätter, and A. Sharov, "Environmental monitoring in the high Arctic using different types of high-resolution satellite imagery", International Archives of Photogrammetry and Remote Sensing, vol. 32, part 7, pp. 201-216, 1998.

[9] B. Csathó, and Toni Schenk, "Multisensor data fusion for automatic scene interpretation", International Archives of Photogrammetry and Remote Sensing, vol. 32, part 7, pp. 336-341, 1998.

[10] S. Houzelle, and G. Giraudon, "Contribution to multisensor fusion formalization," Robotics and Autonomous Systems, vol. 13, pp. 69-85, 1994.

[11] L. Wald, "An overview of concepts in fusion of Earth data," in Proceedings, EARSeL Symposium 1997 "Future Trends in Remote Sensing", Lyngby, Denmark, P. Gudmansen Ed., A. A. Balkema Publ., Rotterdam, pp. 385-390, 1998.

[12] M. Buchroithner, " Geodata interrelations: inventory and structuring attempt of taxonomic diversity," in Proceedings of the 2nd conference "Fusion of Earth data: merging point measurements, raster maps and remotely sensed images", Thierry Ranchin and Lucien Wald Editors, published by SEE/URISCA, Nice, France, pp. $11-15,1998$

[13] L. Wald, "Data fusion: a conceptual approach for an efficient exploitation of remote sensing images," in Proceedings of the $2^{\text {nd }}$ conference "Fusion of Earth data: merging point measurements, raster maps and remotely sensed images", Thierry Ranchin and Lucien Wald Editors, published by SEE/URISCA, Nice, France, pp. $17-23,1998$

[14] A. Bijaoui, Image et segmentation. Introduction au traitement numérique des images. Masson, Paris, 242 pp., 1981.

[15] L. N. Kanal, and A. Rosenfeld, Progress in Pattern Recognition. North-Holland Publ., 391 pp., 1981.

[16] T. M. Lillesand, and R. W. Kiefer, Remote Sensing and Image Interpretation. Third edition. John Wiley \& Sons, 750 pp., 1994.

[17] J. T. Tou, and R. C. Gonzalez, Pattern Recognition Principles. Addison-Wesley Publ., 377 pp., 1974.

[18] T. Ranchin, L. Wald, and M. Mangolini, "The ARSIS method: a general solution for improving spatial resolution of images by the means of sensor fusion," in Proceedings of the $1^{\text {st }}$ conference "Fusion of Earth data: merging point measurements, raster maps and remotely sensed images", Thierry Ranchin and Lucien Wald Editors, published by SEE/URISCA, Nice, France, pp. 53-58, 1996.

[19] T. Ranchin, and L. Wald, "Sensor fusion to improve the spatial resolution of images : the ARSIS method," in : Proceedings, EARSeL Symposium 1997 "Future Trends in Remote Sensing ", Lyngby, Denmark, P. Gudmansen Ed., A. A. Balkema Publ., pp. 445-451, 1998.

[20] S. C. A. Thomopoulos, "Sensor integration and data fusion," Journal of Robotic Systems, vol. 7, pp. 337-372, 1990.

[21] S. C. A. Thomopoulos, "Decision and evidence fusion in sensor integration," in Advances in Control and Dynamic Systems, Ed. C. T. Leondes, vol. 49, part 5, pp. 339-412, Academic Press, 1991.

[22] L. F. Pau, "Sensor data fusion," Journal of Intelligent and Robotics Systems, vol. 1, pp. 103-116, 1988. 